\title{
LOS MAPUCHE Y PERSONEROS DE GOBIERNO EN LA COBERTURA MEDIÁTICA DEL DIARIO CHILENO LA NACIÓN SOBRE EL CONFLICTO CHILENO-MAPUCHE DURANTE EL PRIMER GOBIERNO DE MICHELLE BACHELET JERIA (2006-2010)
}

The Mapuche and government officials as portrayed by Chilean newspaper La Nacion's coverage of the chilean-mapuche conflict, during the first government of Michelle Bachelet Jeria (2006-2010)

Carlos González Aburto* Omar A. Barriga **

Resumen

En este artículo analizamos, en un corpus del diario La Nación, la ideología de la cobertura mediática respecto del conflicto chileno-mapuche durante el primer gobierno de Michelle Bachelet Jeria (2006-2010). En particular, nos preocupa dar cuenta de la forma en que son retratados en este periódico los comuneros indígenas y los personeros de gobierno. Para ello, en primer lugar, describimos la caracterización de estos dos tipos de actores a partir de un análisis de contenido, y luego, en una segunda parte, damos cuenta del panorama ideológico general en donde se insertan estas construcciones. Concluimos que la cobertura del diario se funda en tres puntos nodales: en primer lugar, el "reconocimiento cultural", donde prima la construcción del llamado indio permitido; en segundo lugar, la "seguridad pública", donde predomina la imagen del indio insurrecto. Estos dos puntos, el "reconocimiento cultural" y la "seguridad pública", siempre van en la dirección de insinuar "competencia gubernamental", el tercer punto nodal, entendido como "éxito y destreza en la generación de gobernabilidad", parte fundamental en el proyecto político de la Concertación de Partidos por la Democracia.

Palabras clave: Conflicto chileno-mapuche, La Nación, cobertura periodística, ideología, Concertación de Partidos por la Democracia.

Abstract

In this article we analyze the ideology behind chilean newspaper La Nacion's coverage of the chilean-mapuche conflict, specifically during the first government of Michelle Bachelet Jeria (2006-2010). We try to account for the way both indigenous subjects and government officials are portrayed, characterizing these types of actors, to later, in a second part, attempt to account for the general ideological landscape in which these constructs are inserted. We conclude that the coverage moves between three nodal points: first, "cultural recognition", in which we find the indio permitido; second, "public security", where we find the indio insurrecto. Both these nodal points always seem to imply the third one: "governmental competence", understood as success and skill in generating political governance, a fundamental part of the Concertacion's political project.

Key words: Chilean-mapuche conflict, La Nación, media coverage, ideology, Concertación. 


\section{INTRODUCCIÓN}

Los estudios de prensa han develado sesgos significativos en la forma en que diversas coberturas presentan a los actores involucrados en el conflicto chilenomapuche (Amolef, 2004; Del Valle, 2005; Álvarez, 2011; Troncoso \& González, 2014). Tales estudios, sin embargo, han estado concentrados en diarios de derecha ( $E l$ Mercurio, El Austral de Temuco), centroderecha (La Tercera), o diarios mapuche (Azkintuwe), por lo que aún resulta necesario abordar otros espacios del espectro político-ideológico chileno, más aún si se trata de la ideología que ocupó gran parte de los espacios políticos institucionales desde el fin de la dictadura militar. Esto nos motivó a estudiar la cobertura del diario La Nación acerca del conflicto chilenomapuche, considerándolo un diario de centro-izquierda, progresista, en línea con el proyecto político de la Concertación de Partidos por la Democracia.

Este estudio se presenta en dos partes. En primer lugar, realizamos una revisión de la forma en que dos tipos de actores -los mapuche y los personeros de gobierno- son retratados en la cobertura del diario La Nación durante el primer gobierno de Michelle Bachelet Jeria (2006-2010). En segundo lugar, una vez hechas dichas caracterizaciones, intentamos describir la ideología general en la que estos actores se enmarcan y se relacionan. Para realizar este trabajo hacemos uso de las herramientas teóricas de la tradición de crítica ideológica marxista, en particular los aportes teóricos de Louis Althusser, Ernesto Laclau y Chantal Mouffe. Para la metodología, en tanto, recurrimos a las herramientas del análisis de contenido de Klaus Krippendorf.

\section{FUNDAMENTOS TEÓRICOS}

Esta investigación asume las siguientes premisas teóricas:

1) El diario La Nación (y su respectiva cobertura) será entendido como un aparato ideológico del Estado, de acuerdo con la clásica noción de Louis Althusser (Ideology, 143-146), vale decir, como una institución que busca mediante prácticas significativas -la interpelación ideológica, en este caso, el acto de actualizarse respecto del acontecer noticioso, leer el diario- la constitución de actores devenidos en sujetos sociales, asignándoles un lugar determinado en el esquema social. De aquí que nos interese explorar cuál es la posición que ocupan los actores dentro del corpus del diario, el contenido mismo de la interpelación.

2) El diario La Nación (y su respectiva cobertura) es entendido como parte de un antagonismo social en el sentido de Ernesto Laclau y Chantal Mouffe (1987). Se asume que aspira a realizar una operación hegemónica: el significante "el conflicto chilenomapuche" no tiene un significado en sí mismo, sino que debe ser fijado por las distintas ideologías que compiten entre sí, esto mediante el establecimiento de puntos nodales (por ejemplo, podría llenarse con el punto nodal "violencia terrorista indígena" o "lucha por autonomía territorial"). La búsqueda de estos puntos constituye un requisito necesario para describir y caracterizar la ideología que un aparato ideológico aspira a hegemonizar. 
Los mapuche y personeros de gobierno en la cobertura mediática de La Nación

\section{METODOLOGÍA}

Utilizando las metódicas categorías analíticas ofrecidas por Krippendorf (8387), hemos elaborado el siguiente marco metodológico.

Primer paso: elección de unidades de información a partir de la sistemática delimitación de segmentos del texto que son de interés para los investigadores. Como señalamos, nuestro primer objetivo es obtener una caracterización de los comuneros mapuche y los personeros de gobierno dentro del conflicto chileno-mapuche de acuerdo con la cobertura del diario La Nación. Para ello consideraremos como unidad básica las oraciones con sujeto sintáctico de la cobertura y las respectivas acciones (activas o pasivas) que se les asocian. Ejemplos: "los comuneros demandaron una revisión del juicio", "el ministro prefirió no evaluar la situación del mapuche baleado".

Segundo paso: muestreo. Una vez elegida la forma de las unidades de información, corresponde delimitar el corpus en el que se buscarán aquellas unidades. En este caso, consistirá en todos los artículos objetivos (noticias, crónicas y reportajes) de la cobertura de La Nación sobre el conflicto chileno-mapuche, esto durante el primer gobiemo de Michelle Bachelet Jeria (marzo de 2006 hasta marzo de 2010).

Tercer paso: codificación. Operación por la que atraviesan las unidades de información y que sirve de nexo entre las unidades de texto y la lectura que de ellas hace el investigador. Para esta investigación, en la que se asume que las acciones asociadas con los actores sintácticos son una buena representación del papel que desempeñan en la ideología del diario -después de todo, según Althusser (1971), la ideología asigna lugares a los individuos en el esquema productivo, convirtiéndolos en sujetos sociales-, hemos decidido considerar dos tipos de actores: comuneros indígenas (integrados por tres subtipos: comuneros, líderes indígenas e integrantes de la Coordinadora Arauco Malleco), y personeros de gobierno. Por cierto que hay otros tipos que merecen atención, pero en este artículo centraremos nuestra atención en estos dos grupos.

Cuarto paso: reducción. Una vez puesta toda la diversidad de las unidades en la mesa, y ordenadas de acuerdo con nuestra codificación elegida, corresponde avanzar hacia una reducción de dicha complejidad, vale decir, la reducción es el resultado de pasar las unidades de información por medio de la codificación. Por ejemplo, se puede encontrar varias menciones a comuneros denunciando ser víctimas de violencia policial, por lo que pueden ser reducidos al subtipo "denunciantes de excesiva violencia policial".

Quinto paso: inferencia: mediante la abducción, la información reducida se lleva fuera del ámbito de lo empírico. Lleva la mera descripción del analista hacia lo que dicha información significa, sugiere, provoca o causa. Apunta hacia la originalidad de la investigación realizada.

Aquí es en donde se encuentran los puntos nodales, temas generales que aspiran a llenar el significante "conflicto chileno-mapuche". Por ejemplo, si tenemos subtipos de actores como "denunciantes de excesiva violencia policial", "víctimas de violencia policial", "detenidos" y "los que garantizan seguridad", estos pueden agrupados bajo el punto nodal "seguridad pública". 
Sexto paso: narrar. Mediante este procedimiento se responde a las preguntas de investigación, con la ayuda del marco contextual teórico inicial y de nuevos conceptos que emergen del análisis mismo. Para esta investigación, la narración apunta a una caracterización de la ideología de la cobertura del diario La Nación concerniente al conflicto chileno-mapuche, siempre con la ayuda de los tipos de actores encontrados, es decir, una descripción del contexto en donde estos actores cobran sentido.

\section{RESULTADOS}

\subsection{PRIMERA PARTE: LOS MAPUCHE Y PERSONEROS DE GOBIERNO}

Una vez que se han extraído todas las unidades de información elegidas, se clasificaron y analizaron por los tipos de sujeto sintáctico entre mapuches y personeros de gobierno. De acuerdo con los tipos de actores encontrados, dividimos a los mapuche en tres grandes grupos: los comuneros, sean residentes urbanos o indígenas miembros de comunidades, siempre que no ocuparan cargos; líderes mapuches, figuras que destacan como dirigentes de instituciones o comunidades indígenas (lonkos, intelectuales, líderes de agrupaciones como el Consejo de Todas las Tierras o Identidad Lafkenche, etcétera). Por último, miembros de la Coordinadora Arauco Malleco. Esta división se realizó a base de la forma en eran representados estos tipos en la cobertura, por lo que más que corresponder a una nomenclatura a priori, emergió de nuestro análisis mismo del corpus textual. Esto no ocurrió con los personeros de gobierno, que más allá de diferencias de cargos y funciones, poseían una forma común de ser retratados (es posible señalar que se consideraron autoridades locales o regionales siempre que fueran designadas por el poder ejecutivo, como intendentes y gobernadores, y no los que asumían cargos por votación, como alcaldes y concejales). Mostraremos a continuación nuestros resultados, primero para los tres tipos de mapuche -comuneros, líderes y miembros de la CAM-y luego los personeros de gobierno.

\subsubsection{Comuneros}

El siguiente cuadro muestra un panorama general de los subtipos de la categoría comuneros que encontramos en la cobertura de La Nación, con la cantidad de menciones - unidades de información- para cada año considerado. Considera además dos columnas adicionales: una para la cantidad total de apariciones de cada subtipo, y otra reservada para un resultado final una vez congregados subtipos afines en grupos. 
Los mapuche y personeros de gobierno en la cobertura mediática de La Nación

\begin{tabular}{|l|c|c|c|c|c|c|}
\hline & 2006 & 2007 & 2008 & 2009 & Total subtipos & Total grupo \\
\hline Activistas & 13 & 3 & 16 & 26 & 58 & 67 \\
\hline Declaradores & 11 & 5 & & 4 & 9 & \\
\hline Procesados & & 3 & & & 3 & 39 \\
\hline Condenados & & & 11 & 14 & 25 & \\
\hline Ilegales & & 6 & & & 6 & 15 \\
\hline Culturales & & & 9 & & 9 & 26 \\
\hline Emprendedores culturales & & & 12 & 6 & 18 & \\
\hline Víctimas de violencia & & & & 8 & 8 & \\
\hline $\begin{array}{l}\text { Denunciadores de } \\
\text { violencia }\end{array}$ & & & 7 & 7 & 14 & \\
\hline Familiares & & & & & \\
\hline
\end{tabular}

Hemos construido cuatro grupos para la categoría comuneros a partir de subtipos afines: el primero agrupa a "activistas" y "declaradores", reunidos porque sus acciones y declaraciones siempre tienen un carácter de denuncia de injusticia, de exclusión o reivindicación cultural. El segundo grupo lo integran "procesados", "condenados" e "ilegales" (conjunción de estos dos desde 2008), que juntos suman 39 apariciones a lo largo de la cobertura. El tercer grupo conjuga a "culturales" y "emprendedores culturales", que tienen en común el hecho que resaltan a los comuneros exhibiendo su herencia cultural, totalizando 15 apariciones. Por último, "víctimas de violencia" y "denunciadores de violencia" tienen en común, la violencia de las que son objeto los comuneros de parte de la policía, y suman 26 menciones. El subtipo "familiares" no fue sumado a ninguno de estos grupos, ya que las unidades de texto consideradas podrían sumarse tanto a "ilegales" como a "víctimas de violencia". Son, sin embargo, familiares de comuneros procesados, encarcelados o heridos.

Quisiéramos hacer notar una especie de dualidad que cruza estos subtipos, la que se caracteriza por mostrar, por una parte, a los comuneros haciendo públicas sus reivindicaciones y el rescate de su cultura ("activistas" y "culturales") y, por otra parte, siendo procesados por la policía y la justicia, y siendo víctimas de violencia policial ("ilegales" y "víctimas de violencia"). En los primeros apreciamos un marcado acento puesto sobre los comuneros como sujetos que de manera activa buscan el reconocimiento identitario cultural de su etnia -como se ve en "activistas", el subtipo más recurrente con 58 menciones-, ya sea por medio de marchas, actos culturales, participando en el debate público, ocupando predios, oficinas y embajadas, apoyando a huelguistas u otros "ilegales", etcétera. También, en menor medida, se retrata a los comuneros en medio de actividades culturales (subtipos "culturales" y "emprendedores culturales"), que considerados juntos conforman la cuarta forma de representación más recurrente, con 15 menciones: son sujetos activos, y la cobertura resalta el hecho de que hacen pública su cultura, sea mediante ceremonias, ritos o emprendimientos económicos. Así, concluimos que se retratan a los comuneros como sujetos que rescatan, reproducen y exigen el 
reconocimiento de su cultura y el respeto, resguardo y promoción de la misma, en especial por parte del Estado chileno.

En la segunda mitad de esta dualidad, en tanto, el acento pareciera estar puesto en las transgresiones legales y de seguridad que conllevan una porción considerable de estas acciones políticas reivindicativas: "ilegales", que alcanzan 39 menciones, son la segunda mayoría de menciones para el tipo "comuneros". Resulta curioso que las acciones de violencia misma son escasas veces asignadas a comuneros mapuches. Los comuneros son más bien detenidos o procesados por ser presuntos autores de dichas acciones. Solo cuando están cumpliendo condena -“condenados"- se asumen como autores de delitos. También podríamos agregar a esta parte la violencia sufrida y denunciada por parte de los mismos comuneros, con 26 menciones totales (la sumatoria de "víctimas de violencia" y "denunciadores de violencia").

Ahora bien, estas dos áreas temáticas conformarían los puntos nodales que fijan los significados que sustentan la ideología de la cobertura de La Nación. Quizás esta conclusión sea apresurada, pero teniendo la información de la codificación y la reducción a la vista, nos parece una hipótesis razonable. Así, el significado flotante "conflicto chileno-mapuche" busca ser fijado con los puntos reconocimiento cultural y seguridad pública. Aquí, un cuadro resumen del análisis:

\begin{tabular}{|c|c|}
\hline Reconocimiento Cultural & Seguridad Pública \\
\hline $\begin{array}{c}\text { Activistas, declaradores, culturales, emprendedores } \\
\text { culturales. }\end{array}$ & $\begin{array}{l}\text { Detenidos, procesados, ilegales, víctimas de } \\
\text { violencia, denunciadores de violencia. }\end{array}$ \\
\hline
\end{tabular}

Resulta importante que dentro de lo que hemos llamado como "reconocimiento cultural" no existan muchas menciones en torno a los aspectos políticos más formales o "puros". Hay bastantes menciones acerca de salud y educación intercultural, la protección y promoción de la cultura e identidad, y cómo distintos proyectos productivos de gran escalaforestales e hidroeléctricas- afectan a las comunidades. En ese sentido, existen escasas unidades de información que versen respecto de la autodeterminación (aunque destaca la cobertura sobre la fundación del partido Wallmapuwen) o el control territorial. Más adelante ofreceremos una interpretación más acabada de esta característica de la cobertura.

Otro punto que nos pareció relevante fue que estudios anteriores de diarios de derecha y centroderecha (Amolef, 2004; Del Valle, 2005; Álvarez, 2011; Troncoso \& González, 2014) encontraron que, cuando los indígenas eran sujetos activos, estas coberturas acentuaban las consecuencias negativas de sus acciones, y cuando eran sujetos pasivos -como en la recepción de beneficios y políticas estatales- eran retratados en una luz neutral o positiva. En La Nación, si bien es cierto que una parte considerable de la cobertura sigue esta línea, hay otra parte de ella que los muestra siendo activos pero con connotaciones neutrales, como en los activistas, o positivas, como en los multiculturales (para ejemplos sobre los que construimos estos subtipos, puede consultarse el anexo). Es decir, en la cobertura de La Nación, los indígenas pueden ser agentes activos positivos, o al menos sin connotaciones negativas. 
Esta desavenencia deriva de la diferencia entre poner un énfasis casi exclusivo en los aspectos negativos de la violencia indígena, y ofrecer una tribuna para mostrar a los indígenas en otra luz que no involucren la temática de seguridad pública. La novedad de la cobertura de La Nación reside así en la incorporación del "reconocimiento cultural", lo que permite otorgar más profundidad a las representaciones de indígenas, entregándole además cierta hondura a la violencia indígena como una parte - no tolerada por parte del gobierno- de un proyecto reivindicativo mayor. Puede existir así el sujeto mapuche activo neutral o positivo.

Esta dualidad coincide con una distinción importante trabajada por Hale (16-21) y Richards (59-90), quienes desarrollan la diferencia entre el "indio permitido" y el "indio insurrecto". Para ellos, el capitalismo o neoliberalismo multicultural es un proyecto cultural que ha expandido la voluntad de los Estados en cuanto al reconocimiento de derechos indígenas. En Chile, esta política puede rastrearse desde la creación de la Corporación Nacional de Desarrollo Indígena en 1993, hasta la aprobación del Convenio № 169 de la Organización Internacional de Trabajo de 2009, entre otras políticas afines. Este nuevo escenario cultural nace en parte por el reconocimiento por parte de los Estados contemporáneos de las consecuencias negativas que han resultado tras un largo tiempo de políticas de asimilación (Richards, 65) - o en el caso de Chile, de despojo, conquista militar y asimilación cultural-, que constituyeron acciones que buscaban la instauración y consolidación de los proyectos nacionales. Sin embargo, las reivindicaciones indígenas no siempre coinciden con el área en el que el Estado quiere otorgar reconocimiento en un área en particular: el desarrollo económico. Los conflictos entre las empresas madereras Arauco y Mininco y los indígenas, o la notoria polémica acerca de la construcción de la central hidroeléctrica Ralco de parte de Endesa S.A. serían testimonio de este límite que separaría al "indio permitido" del "indio insurrecto".

El "indio permitido" es representado dentro de los márgenes de reconocimiento cultural delineados por el Estado. Los "activistas" son apreciados en la medida en que expresan un afán de su pueblo por la consideración de su cultura bajo la forma del otorgamiento de ciertas demandas. El "indio insurrecto", en tanto, es aquel que, si bien puede poseer aquel mismo afán, opta por poner en cuestión las prerrogativas básicas del Estado (Hale, 19), rechazando los márgenes de negociación que ha demarcado como válidos, considerándolos insuficientes, incluso engañosos. Aparece así fuera de los límites políticos permitidos.

En el caso específico de la cobertura de La Nación, no aparecen realizando los actos (quema de instalaciones, máquinas, vehículos, predios, etcétera; ataque a autoridades policiales y fiscales, acciones reservadas para sujetos étnicamente neutrales: "encapuchados" y "desconocidos"), sino siendo acusados, procesados y condenados por hacerlos.

Hemos complementado el cuadro construido en principio con nueva información: la distinción indio permitido/indio insurrecto. El primero de ellos hace alusión a las temáticas de reconocimiento cultural, mientras que el segundo persiste en los aspectos de seguridad pública de la cobertura. 


\begin{tabular}{|cc|}
\hline Reconocimiento Cultural & Seguridad Pública \\
Activistas, Declaradores, Culturales, Emprendedores & culturales \\
"Indio Permitido" & $\begin{array}{c}\text { Detenidos, procesados, ilegales, víctimas de } \\
\text { violencia, denunciadores de violencia }\end{array}$ \\
"Indio Insurrecto"
\end{tabular}

\subsubsection{LÍDERES MAPUCHES}

Al igual que con los comuneros mapuches, comenzaremos la exposición de los líderes indígenas con la presentación de la tabla de frecuencia de los subtipos encontrados para estos actores.

\begin{tabular}{|l|c|c|c|c|c|c|}
\hline & 2006 & 2007 & 2008 & 2009 & Total subtipos & Total grupo \\
\hline Violentos & 5 & & & & 5 & 29 \\
\hline Ilegales & 7 & & 4 & & 11 & \\
\hline Procesados y condenados & & 5 & & & 5 & \\
\hline Huelguistas & & 8 & & & 8 & \\
\hline $\begin{array}{l}\text { Declaradores contra el } \\
\text { excesivo control }\end{array}$ & & & 4 & 3 & 7 & 17 \\
\hline Denunciantes de violencia & & & & 10 & 10 & \\
\hline Políticos & 6 & & & & 6 & 38 \\
\hline Declaradores multiculturales & & 2 & 3 & 4 & 9 & \\
\hline Activos & & & 7 & & 7 & \\
\hline Propositivos & & & & 4 & 4 & \\
\hline Críticos del gobierno & & & & 7 & 7 & \\
\hline No recibidos & & & & 5 & 5 & \\
\hline
\end{tabular}

Con los subtipos encontrados hemos construido tres grupos: el primero, con 29 apariciones, está constituido por los subtipos "violentos", "ilegales", "procesados y condenados" y "huelguistas". La temática común que permite agruparlos es que en todos los subtipos los líderes aparecen siendo procesados o cumpliendo condenas por actos de violencia. Los "huelguistas", en tanto, corresponden a los condenados por Ley Antiterrorista como autores del incendio del fundo Poluco-Pidenco, de la Forestal Mininco, quienes piden la revisión de sus casos, el otorgamiento de beneficios carcelarios y que se retire el uso de la Ley Antiterrorista, entre otras peticiones.

El segundo grupo está formado por "declaradores contra el excesivo control" y "denunciantes de violencia", con 17 apariciones, en donde dirigentes mapuches, que no están siendo procesados o condenados por actos de violencia, aparecen denunciando la violencia y el excesivo control o presencia policial al que están sometidas sus comunidades. Este nuevo grupo de subtipos tiene mayor relación, con el punto nodal "seguridad pública", sobre todo porque refiere a una consecuencia del tratamiento del tema desde la perspectiva de la seguridad nacional. Curiosamente, la violencia de la que son objeto los comuneros -0 al menos la preocupación que existe de parte de ellos respecto del actuar de la policía- es un tema recurrente en la cobertura. Este aspecto es pocas veces considerado en otras coberturas, de acuerdo con los estudios que hemos nombrado antes. 
El tercer grupo, en tanto, lo forman los subtipos "políticos", "declaradores multiculturales", "activos", "propositivos", "críticos del gobierno" y "no recibidos". Este grupo, si bien es bastante más heterogéneo que el anterior, aún contiene cierta temática común a todos los subtipos que la integran: una discusión activa por parte de los líderes indígenas acerca de los intereses del pueblo mapuche, ya sea por los caminos políticos que deben seguirse para avanzar su causa, opinando respecto de distintas medidas y políticas propuestas por el gobierno, y también sugiriendo o planteando iniciativas propias. Los no recibidos también son activos, en la medida en que buscan instancias de conversación o la entrega de ciertos documentos, solo que no obtuvieron respuesta ni audiencia de parte de las autoridades. Además, se denuncia lo que consideran el excesivo contingente policial presente en la zona, y la aplicación de leyes de excepción en contra de los comuneros y líderes apresados.

Así, podemos complementar el cuadro que construimos finalizando el análisis de los comuneros indígenas, en donde clasificamos los subtipos de actores de acuerdo con los dos puntos nodales que, a nuestro juicio, fundan la cobertura hasta el momento.

\begin{tabular}{|ccc|}
\hline Punto Nodal & Reconocimiento Cultural & Seguridad Pública \\
& Indio Permitido & Indio Insurrecto \\
Políticos, declaradores & Violentos, ilegales, procesados y \\
Dirigentes Indígenas & $\begin{array}{c}\text { multiculturales, activos, propositivos } \\
\text { críticos del gobierno, no recibidos. }\end{array}$ & $\begin{array}{c}\text { condenados, huelguistas, declarantes } \\
\text { col excesivo control, denunciantes } \\
\text { de violencia. }\end{array}$ \\
\hline
\end{tabular}

\subsubsection{LA COORDINADORA ARAUCO-MALLECO}

Se expone a continuación la tabla de frecuencias para los subtipos de actores que integran la Coordinadora Arauco-Malleco.

\begin{tabular}{|l|c|c|c|c|c|}
\hline & 2006 & 2007 & 2008 & 2009 & Total subtipos \\
\hline Ilegales & & & 15 & 14 & 29 \\
\hline Los que alegan inocencia & & & 3 & & 3 \\
\hline Institución & & & 4 & & 4 \\
\hline Huelguistas & & & & 2 & 2 \\
\hline Adjudicadores de atentados & & & & 3 & 3 \\
\hline
\end{tabular}

La Coordinadora Arauco Malleco es por lejos la institución mapuche más polémica en el marco del conflicto chileno-mapuche. La Coordinadora emerge desde 1997 como una forma novedosa de hacer política desde lo indígena. Como señalan Pairicán y Álvarez, junto con el crecimiento y explosión de la actividad forestal en los 80 , comenzó a formarse una nueva generación de mapuches críticos, que comenzaron a acentuar sus diferencias con la nueva institucionalidad indígena creada en la década de los 90, con especial énfasis en la CONADI (70). La primera acción se llevó a cabo en 1997, con la quema de tres camiones de Forestal Arauco. Con esto, la Coordinadora buscaba explicitar una política de "control territorial". En la cobertura revisada, hemos contado 41 unidades de información correspondientes a ella o los miembros que la integran. 
Debido a esta naturaleza reivindicativa, que recurre como uno de sus métodos de acción a la destrucción de la propiedad privada, no es extraño que sus integrantes aparezcan casi exclusivamente en acciones relacionadas con las consecuencias judiciales de su actuar. En bastante menor medida, aparecen adjudicándose atentados. Vale decir, aunque sus acciones contengan no solo una reflexión teórica, sino también se contextualicen, a juicio de ellos, dentro del fracaso o insuficiencia del Estado para hacer frente a la relegación indígena, lo único que se resalta es la violencia de sus acciones o lo polémico de la aplicación de leyes de excepción. Por lejos la categoría más presente es aquella de "ilegales", que muestra a los miembros de la CAM siendo procesados, condenados o cumpliendo penas de cárcel por sus acciones reivindicativas violentas. A este total pueden sumarse, sin mayores problemas temáticos, el subtipo "huelguistas", que son miembros de la CAM condenados por ley antiterrorista y que, mediante una prolongada huelga, buscaban beneficios carcelarios y la revisión de sus casos.

Hablaremos ahora acerca de la función o rol que ocupan los miembros de la Coordinadora en la cobertura de La Nación. Por cierto que, cuando consideramos el punto nodal de la seguridad pública, en esta cobertura hay elementos símiles a los encontrados por otros investigadores en diarios de derecha y centroderecha: violencia indígena contra empresas y privados, control policial y enfrentamientos con Fuerzas Especiales, juicios y encarcelamientos, etc. Sin embargo, en este diario estos actos de violencia están ceñidos solo a menciones de la Coordinadora, y no a otros grupos o a los mapuches en general. Hacer esto y poner énfasis en los mapuches violentos de forma muy explícita o como el principal eje del conflicto -como en las investigaciones sobre El Mercurio, La Tercera y El Austral realizadas por de Amolef (2004), Del Valle (2005), Álvarez (2011) y Troncoso y González (2014)- creemos que puede ir en detrimento de la reputación o imagen pública de un gobierno progresista. Esto es, desde el gobierno, y como se refleja luego en el análisis de sus personeros, se tienen dos prioridades: hacer valer el estado de derecho y la mantención de la seguridad pública, y un intento, con diferentes grados de éxito y fracaso, por incorporar aspectos de la cultura indígena (comida, salud, lengua, etcétera) a la cultura institucional del país, vale decir, políticas multiculturales. Entonces, para evitar una generalización de los mapuches como violentistas, La Nación puede seleccionar al grupo que más recurre a ella, y centrar la denuncia del mapuche violento -"el indio insurrecto"- en ellas. De una forma, la Coordinadora y sus miembros son una especie de chivo expiatorio, sobre el que se pueden verter las nociones de indígena insurrecto, y esquivar el sesgo racista o polémico que puede connotar esta acusación. Tratar el tema de la violencia se transforma así, en primer lugar, en el control de grupos extremistas, subversivos y poco razonables, y no en nuevas formas de hacer frente a la tensión entre las consecuencias inesperadas de la modernidad y las soluciones institucionales ofrecidas para resolverlas. Los miembros de la Coordinadora Arauco Malleco, entonces, cumplen el rol de indígenas violentos, lo que permite al gobierno enfatizar la seguridad pública. 
Como tal, no sorprende que la CAM y sus miembros aparezcan ligados al punto nodal de seguridad pública, en especial a la construcción del "indio insurrecto". Podemos así finalizar este análisis con la presentación del cuadro de puntos nodales respectivos.

\begin{tabular}{|ccc|}
\hline Punto Nodal & $\begin{array}{c}\text { Reconocimiento Cultural } \\
\text { Indio Permitido }\end{array}$ & $\begin{array}{c}\text { Seguridad Pública } \\
\text { Indio Insurrecto }\end{array}$ \\
$\begin{array}{c}\text { Miembros de la Coordinadora } \\
\text { Arauco Malleco }\end{array}$ & - & $\begin{array}{c}\text { "Ilegales", "los que alegan inocencia", } \\
\text { "la institución", "huelguistas", } \\
\text { "adjudicadores de atentados" }\end{array}$ \\
\hline
\end{tabular}

\subsubsection{PERSONEROS DE GOBIERNO}

Comenzaremos este análisis con una exposición del cuadro que resume el resultado de la codificación y la reducción de este tipo de actores. Como en cuadros anteriores, hemos conjugado en grupos afines a los distintos subtipos de personeros de gobierno:

\begin{tabular}{|l|c|c|c|c|c|c|}
\hline & 2006 & 2007 & 2008 & 2009 & Total subtipos & Total grupo \\
\hline Hacedores & 5 & & & & 5 & 64 \\
\hline Propositivos & & 4 & & & 4 & \\
\hline Activos & & & & 27 & 27 & \\
\hline Declarantes & & 4 & & & 4 & \\
\hline Multiculturales & 3 & & 21 & & 24 & \\
\hline Cautelosos & 3 & & & & 3 & 22 \\
\hline Negociadores & & 2 & 6 & & 8 & \\
\hline Autorreflexivos & & & 11 & & 11 & \\
\hline Los que llaman a la calma & & & 8 & & 8 & 84 \\
\hline Los que bajan el perfil a la violencia & & & & 21 & 21 & \\
\hline Los que garantizan seguridad & & & 18 & 13 & 31 & \\
\hline Condenadores de violencia & & & & 11 & 11 & \\
\hline Querellantes & & & & 13 & 13 & \\
\hline $\begin{array}{l}\text { Los que rechazan la especulación de } \\
\text { tierras }\end{array}$ & & & & 4 & 4 & \multirow{2}{*}{} \\
\hline
\end{tabular}

El primer grupo ("hacedores", "propositivos", "activos" y “declarantes") muestra a los personeros de gobiemo en posiciones de acción o agenciamiento resolutivo: proponen soluciones, ejecutan programas, planifican estrategias, resaltan la importancia de medidas y convocan a reuniones o encuentros entre los diferentes actores involucrados en el conflicto. Otra característica de este grupo es que la mayor parte de estas medidas conllevan un aspecto de "reconocimiento cultural": se resaltan cambios de dirigentes en el programa Orígenes o en CONADI, el nombramiento de nuevas instancias para avanzar en la temática indígena, nueva legislación que avanza en el reconocimiento de derechos indígenas, nuevos fondos para compras de tierras o becas indígenas, etc. También integran este grupo los "multiculturales". En principio, quizás guiado por los nombres, los habíamos puesto en una categoría propia, pero una revisión más detallada revela que comparten las dos características que distinguen al primer grupo: agenciamiento y resolución, y una voluntad de trabajar en el tema de reconocimiento cultural de los 
mapuches. Al final, este grupo se presenta con la segunda mayoría de menciones, con un total de 64 apariciones (o unidades de información).

El segundo grupo ("cautelosos", "negociadores" y "autorreflexivos") muestra a personeros en la administración y ejercicio del poder, más que en una posición característica del conflicto chileno-mapuche. Sin embargo, aquello no significa que esta caracterización no cumpla un rol en el marco de la cobertura del diario. Creemos que se trata, en este caso, de distanciarse de la imagen de poseer una postura o una actitud extrema o intransigente, o más bien, de parecer razonables, con buena disposición y con la situación bajo control. De esa forma se puede explicar la cautela de los personeros de gobierno en sus declaraciones, en donde no quieren parecer presurosos; se puede explicar también su aceptación de las condiciones de la huelguista Patricia Troncoso ("negociadores"); por último, también explica su reflexividad, mediante ella pueden asumir una postura crítica respecto de medidas o políticas anteriores (en parte porque permite reforzar las nuevas medidas, que no contienen las mismas debilidades que las anteriores). También nos parece que este segundo grupo, si bien distinto del primero, posee sin embargo una afinidad con él: comparte, en el fondo, una actitud de aceptación y trabajo hacia el reconocimiento de la cultura indígena y las necesidades más contingentes del conflicto.

El tercer grupo que emerge del análisis está constituido por "los que llaman a la calma", "los que bajan el perfil a la violencia", "los que garantizan seguridad", "los condenadores de violencia" y "querellantes", vale decir, por quienes generan respuestas a la parte más violenta del conflicto. Estas respuestas consisten, a nuestro juicio, en diferentes técnicas para significar la violencia, ofrecer una interpretación de ella, mediante diferentes técnicas, las que exploraremos enseguida.

En primer lugar, "condenadores de violencia" son personeros que rechazan la violencia en el conflicto, sea cual sea su fuente: la violencia indígena de la Coordinadora Arauco Malleco o de algunas comunidades; del Comando Hernán Trizano, que de manera pública ha amenazado con violencia y muerte a varios dirigentes mapuches; o la violencia excesiva de la policía. Por supuesto que la violencia, como bien lo prueba la cantidad de menciones totales de estos subtipos agrupados (primera mayoría, con 84 menciones), pareciera ser el origen de muchos de los problemas -más urgentes, por cierto- que debe resolver el gobierno. De ahí que una de las formas de ser consistente con su condena, al menos en su versión indígena, es en la forma de "querellantes": la puesta en Tribunales de acciones legales en contra de la quema de predios, camiones y fundos, muchas veces utilizando las leyes de excepción (Ley Antiterrorista o Ley de Seguridad del Estado). Lo mismo para "los que garantizan seguridad" mediante medidas que pretenden reforzar la seguridad de la zona, ya sea por medio de la disuasión legal, la amenaza de la aplicación de las leyes de excepción, o la inversión en seguridad pública y vial.

En segundo lugar, los subtipos "los que llaman a la calma" y "los que bajan el perfil a la violencia" utilizan la técnica de minimizar la violencia indígena o sus consecuencias, en parte para desestimar versiones que hablarían, según ellos mismos, de una guerra civil o de células terroristas, y por otra para proyectar una imagen de control 
sobre la situación. El gobierno no puede hacer oídos sordos y objetar la existencia o relevancia de la violencia: hay personas afectadas por ella, y se trata de un fenómeno recurrente; por otra, no pueden aceptar la existencia de descontrol o de una vorágine de violencia, ya que se denunciarían a sí mismos como incompetentes. Estas técnicas recién exploradas buscan, entonces, lograr un equilibrio entre dos posturas: reconocer la existencia de la violencia, pero no a un nivel que ponga en duda la competencia y capacidad del gobierno para controlarla. Por último, una tercera técnica consiste en señalar que los indígenas que usan la violencia son una minoría, y que no representan "a la tradición ni a los intereses del pueblo mapuche" (La Nación, 30 julio 2009: 7). La marginalización de estos grupos justifica, después, las reacciones del gobierno cuando recurre al control social, sobre todo en sus aspectos más polémicos: se está reprimiendo a sujetos desmesurados, y no a una etnia en particular.

Los grupos recién explorados coinciden con el punto nodal "reconocimiento cultural". El gobierno debe representarse a sí mismo (La Nación es un diario oficialista) como competente y abierto hacia las demandas del multiculturalismo (además de catalizador del consenso), y actuando con resolución por ese camino. Por otra parte, el cómo hacer frente a la violencia (y posicionarla ante el público o sociedad civil) corresponde al punto nodal "seguridad pública". Extenderemos así el cuadro para agregar lo recién analizado.

\begin{tabular}{|c|c|c|}
\hline Point de Capiton & Reconocimiento Cultural & Seguridad Pública \\
\hline & Indio Permitido & Indio Insurrecto \\
\hline Comuneros Mapuche & $\begin{array}{l}\text { Activistas, declaradores, } \\
\text { culturales, emprendedores } \\
\text { culturales. }\end{array}$ & $\begin{array}{c}\text { Detenidos, procesados, ilegales, } \\
\text { víctimas de violencia, denunciadores } \\
\text { de violencia. }\end{array}$ \\
\hline Dirigentes Indígenas & $\begin{array}{l}\text { Políticos, declaradores } \\
\text { multiculturales, activos, } \\
\text { propositivos, críticos del } \\
\text { gobierno, no recibidos. }\end{array}$ & $\begin{array}{l}\text { Violentos, ilegales, procesados y } \\
\text { condenados, huelguistas, declarantes } \\
\text { contra el excesivo control, } \\
\text { denunciantes de violencia. }\end{array}$ \\
\hline Personeros de Gobierno & $\begin{array}{l}\text { Hacedores, activos, } \\
\text { propositivos, declarantes, } \\
\text { cautelosos, negociadores, } \\
\text { autorreflexivos, } \\
\text { multiculturales. }\end{array}$ & $\begin{array}{c}\text { Los que llaman a la calma, los que } \\
\text { bajan el perfil a la violencia, los que } \\
\text { garantizan seguridad, los } \\
\text { condenadores de violencia, } \\
\text { querellantes. }\end{array}$ \\
\hline Comuneros Mapuche & $\begin{array}{l}\text { Activistas, declaradores, } \\
\text { culturales, emprendedores } \\
\text { culturales. }\end{array}$ & $\begin{array}{c}\text { Detenidos, procesados, ilegales, } \\
\text { víctimas de violencia, denunciadores } \\
\text { de violencia. }\end{array}$ \\
\hline Dirigentes Indígenas & $\begin{array}{l}\text { Políticos, declaradores } \\
\text { multiculturales, activos, } \\
\text { propositivos, críticos del } \\
\text { gobierno, no-recibidos. }\end{array}$ & $\begin{array}{c}\text { Violentos, ilegales, procesados y } \\
\text { condenados, huelguistas, declarantes } \\
\text { contra el excesivo control, } \\
\text { denunciantes de violencia. }\end{array}$ \\
\hline Personeros de Gobierno & $\begin{array}{l}\text { Hacedores, activos, } \\
\text { propositivos, declarantes, } \\
\text { cautelosos, negociadores, } \\
\text { autorreflexivos, multiculturales. }\end{array}$ & $\begin{array}{c}\text { Los que llaman a la calma, los que } \\
\text { bajan el perfil a la violencia, los que } \\
\text { garantizan seguridad, los condenadores } \\
\text { de violencia, querellantes. }\end{array}$ \\
\hline
\end{tabular}




\subsection{SEGUNDA PARTE: LA IDEOLOGÍA DE LA NACIÓN}

\subsubsection{LA COMPETENCIA GUBERNAMENTAL: UN NUEVO PUNTO NODAL}

Durante varios momentos de la inferencia intuimos la existencia de un tercer punto nodal, reservando un análisis más profundo para este momento. Así, a los dos puntos nodales que guiaron nuestro análisis de los actores, el reconocimiento cultural y la seguridad pública, quisiéramos agregar otro: la competencia gubernamental. Por competencia gubernamental entendemos algo parecido a lo que en ciencias políticas se denomina gobernabilidad: en la definición de Camou, "se entiende un estado de equilibrio dinámico entre el nivel de las demandas societales y la capacidad del sistema político para responderlas de manera legítima y eficaz" (10). Se trata de un concepto relacional y multidimensional (Camou, 10): relacional, porque emerge de las tensiones entre las expectativas de la ciudadanía para con la modernización, y el sistema político e institucional que la encausa; multidimensional, porque para una comprensión de esta relación se requiere, necesariamente, de la consideración de múltiples variables y perspectivas: economía, cultura, sexualidad, etnicidad, trabajo, etc. Gobernabilidad refiere entonces a la medida en que la institucionalidad política logra reflejar, con éxito, los deseos de la ciudadanía por medio de sus instituciones.

Hay una razón más contextual para nuestro uso del concepto gobernabilidad: varios miembros clave de la Concertación (Boeninger, 1994; Insulza, 2010) se refieren de manera constante a ella como uno de los ejes de su proyecto de democracia. En tal sentido, cuando bautizamos el tercer punto nodal como competencia gubernamental, buscábamos en parte tomar su significado del concepto de gobernabilidad, pero también queríamos expandirlo más allá de él. Para nosotros, este punto nodal no solo indica una aspiración a la consolidación de un régimen institucional democrático que satisfaga las demandas sociales, sino que además sugiere éxito y destreza en tal empresa. Así, podríamos resumir el punto nodal "competencia gubernamental" como éxito y destreza en la creación y mantención de gobernabilidad.

Así, las demandas de los mapuches son uno de los desafíos hacia la gobernabilidad, uno de los aspectos de la multidimensionalidad que la caracteriza. Estas demandas emergen como una exigencia que interpela al sistema político, y guardando un juicio acerca de que si la respuesta del ejecutivo es acertada, legítima, eficiente o moral, el gobierno hace frente a dicho emplazamiento mediante su política indígena que, como hemos visto, consiste en el reconocimiento cultural y la seguridad pública. Así, nuestros dos primeros puntos nodales son una forma de crear, promover y dar la impresión de una gobernabilidad exitosa. Para entender bien sus implicancias, analizaremos el punto nodal "competencia gubernamental" en relación con los otros dos puntos.

\subsubsection{LA “COMPETENCIA GUBERNAMENTAL" Y LA "SEGURIDAD PÚBLICA"}

El primer indicio de este nuevo punto nodal, y quizás el más aparente, son varios subtipos que aparecieron en el análisis de "los personeros de gobierno", específicamente el 
grupo de personeros que responde a la violencia indígena. Esto requiere de un análisis detenido: se tiene, por una parte, a "los condenadores de violencia", "los que garantizan seguridad" y "los querellantes", que pueden caracterizarse como las acciones concretas del gobierno en respuesta a la violencia indígena. Por otra parte están "los que llaman a la calma" y "los que le bajan el perfil a la violencia", que puede decirse conforman los intentos del gobierno por darle una narración a dicha violencia, otorgándole una significancia específica que, desde luego, más tarde buscan difundir en el público.

De acuerdo con esta distinción, se puede afirmar que la "competencia gubernamental", cuando hace frente a la violencia reivindicativa indígena, aparece en dos momentos: 1) cuando se refuerza la necesidad y, en consecuencia, la legitimidad de las instituciones del Estado, lo cual hace el gobierno mediante sus respuestas activas hacia la violencia indígena: su condena pública y la reafirmación del diálogo como vía para soluciones, y el control policial y judicial, o en otras palabras, las acciones del primer grupo de subtipos descrito del párrafo anterior ("los condenadores de violencia", "los que garantizan seguridad" y "querellantes"). 2) Cuando el gobierno reconoce que si bien la violencia indígena se trata de un problema real, se dedica a restarle las connotaciones de exceso, descontrol o desmesura, para ello recurre a la significación de la violencia: el segundo grupo de subtipos del párrafo anterior ("los que llaman a la calma" y "los que le bajan el perfil a la violencia").

Resulta interesante constatar que estas dos dimensiones coinciden, de buena manera, con la clásica distinción althusseriana entre "aparatos represivos del Estado" y "aparatos ideológicos del Estado". Los aparatos represivos se caracterizan por operar por medio de la violencia, no solo física (como por ejemplo, la represión administrativa). El mismo Althusser (Ideología, 142-143) los enumera: el gobierno, la administración, el ejército, la policía, las cortes, las prisiones, etcétera. Vale decir, son representaciones del monopolio del uso legítimo de la violencia. La "competencia gubernamental" se ve, entonces, en el uso de la fuerza legítima estatal, en sus diversas encarnaciones recién enumeradas, para frenar la violencia política mapuche.

Los aparatos ideológicos del Estado, por su parte, funcionan "mediante la ideología", vale decir, por medio de la producción de "representación de las relaciones imaginadas de los individuos con las condiciones reales de su existencia" (For Marx 233-234, traducción propia). Estas representaciones de actores compiten con otras para fijarse como el significado dominante. En ese sentido, los personeros de gobierno caracterizan a los indígenas violentos de la siguiente manera: no están fuera de control, no constituyen células terroristas, y no representan la mayor parte del sentir de los mapuche en general. Esta representación tiene, para nosotros, tres funciones: 1) no sobredimensionar la violencia en La Araucanía, evitando dejar como incompetente al gobierno; 2) una aislación de los indígenas violentos, como un grupo específico y definido que no representa el sentir mayoritario del pueblo mapuche; y 3) legitimar el uso de los aparatos represivos del Estado. 
El reforzamiento de la relevancia, competencia y legitimidad de la institucionalidad estatal es un trabajo importante para la búsqueda y construcción exitosa de la competencia gubernamental. También lo es demostrar que, si bien se presentan problemas, en este caso de violencia indígena, estos no representan un abierto desafío a la legitimidad del gobierno y sus instituciones, sino simplemente un problema que debe resolverse con la mezcla adecuada de políticas de reconocimiento y control. Esto se puede hacer echando mano a los aparatos del Estado: los aparatos represivos para el control de las consecuencias materiales de la violencia indígena (policía y tribunales), y los aparatos ideológicos (como el diario La Nación) para el control de las consecuencias simbólicas de aquella violencia: la violencia no es tan grave, es un grupo marginal radicalizado, etcétera.

\subsubsection{LA "COMPETENCIA GUBERNAMENTAL" Y EL "RECONOCIMIENTO CULTURAL"}

Como mencionamos, lo que distingue a la cobertura de La Nación acerca del conflicto chileno-mapuche de otras coberturas estudiadas, es la atención a la temática de reconocimiento cultural, en donde actores mapuches asumen roles activos con connotaciones neutrales o positivas. Estas apariciones se relacionan con sujetos indígenas al rescate de su identidad, mediante actividades, ritos y ceremonias propias de su cultura: celebrando el We txipantu, jugando al palín, creando jardines infantiles mapuches, proyectos de educación intercultural bilingüe, la apertura de farmacias y centros de salud mapuche, etc. Esto indica una preocupación por cubrir el quehacer de las comunidades mapuches, tanto urbanas como rurales, fuera del ámbito de la violencia. Resta preguntarse entonces por la función de estas apariciones, y para ello hay que explorar en forma breve la disposición de la Concertación en materia indígena y, por sobre todo, respecto de la gobernabilidad.

Está claro que cierto reconocimiento cultural siempre fue un objetivo de la Concertación: la creación de la Conadi y la Ley Indígena, el programa Orígenes, la Comisión Verdad Histórica y Nuevo Trato con los Pueblos Indígenas, la ratificación del Convenio 169 de la OIT, etc., entre otras medidas, revelan cierta voluntad en esta dirección. Como bien señala Richards (68-69), el Estado chileno, guiado por la Concertación, ha instituido políticas para reconocer algunos derechos indígenas y promover diversidad en la sociedad chilena. La discusión o polémica gira en torno, más bien, al alcance o efectividad de dichas medidas para resolver la problemática indígena, la forma en que aquellos proyectos fueron implementados, el grado de participación que se le dio a las indígenas en la concepción y ejecución de dichos proyectos y, por supuesto, los supuestos teóricos que fundamentan su visión general sobre multiculturalismo. Claro está, sin embargo, que aquello no guarda relación con los objetivos de esta investigación. Lo que sí nos interesa es cómo esta perspectiva de gobierno se expresa por medio de la cobertura.

Esta preocupación de los gobiernos de la Concertación por desarrollar una política indígena inclusiva se aprecia en varios momentos de la cobertura. La primera y más obvia son el conjunto de políticas multiculturales que aparecen siendo promovidas desde el gobierno, en particular los subtipos clasificados como "multiculturales". Dichos funcionarios aparecen en posiciones activas y resolutivas, realzando una actitud de 
decisión de parte de estos. Su contraparte correspondiente, o el lugar de llegada de dichas políticas, son los subtipos indígenas "emprendedores culturales" y, de manera más indirecta, los "culturales". Estos tipos son cualitativamente diferentes: los primeros son beneficiarios de ayuda estatal que les permite insertarse en el mercado nacional con elementos de su identidad originaria; los segundos aparecen, más bien, en medio de actos en donde se destaca su herencia cultural. Esta distinción señala dos aspectos diferentes pero ligados: primero, el fomento a la inserción de elementos culturales mapuche al mercado; segundo, el hacer visible o exponer ciertos elementos de la cultura mapuche, ritos y objetos culturales, al público lector de La Nación.

Puede argüirse que este tipo de exposiciones contienen, por lo general, aspectos poco polémicos desde el punto de vista político y económico: por ejemplo, aparecen celebrando nguillatunes, pero no reuniones en donde se discute la autonomía territorial. Bello Maldonado, hablando del gobierno de Lagos, sostiene que dicha administración era guiada por "la contención política destinada a dar gobernabilidad a un modelo económico sobre el cual existe un alto consenso entre las capas dirigentes" (39). En ese sentido, uno de los desafios de la gobernabilidad es generar un consenso que ayude a sostener el modelo económico y, en seguida, hay demandas mapuches que desafian el desarrollo del libre mercado, o al menos el de las grandes inversiones, como las forestales (Arauco y Mininco) y las hidroeléctricas (Endesa). Sería en este terreno en donde se muestran los aspectos más crudos del conflicto, reservándose las demostraciones de cultura mapuche para aquellos espacios que no proponen obstáculos a la implementación de tal proyecto. Se hace relevante, de nuevo, la distinción entre indio permitido e indio insurrecto. Hemos dicho que el indio insurrecto es el que prima en la cobertura en torno a la seguridad pública: un agente problemático, marginado por los procesos de modernización, contestatario de los proyectos desarrollistas, que rechaza los caminos institucionalizados y reclama de manera testaruda por autonomía con actos de violencia. En cambio, el indio permitido va de la mano con la apertura de la economía de mercado, ya no una fuerza que impone un único modelo cultural para la expansión del mismo, sino uno que se muestra abierto a la incorporación de nuevas culturas mientras se rijan por su lógica. Richards lo expresa de forma sucinta: "muchas de estas políticas se condicen directamente con valores neoliberales, poniendo énfasis en un aumento del acceso de individuos indígenas al mercado (...) que incluyen proyectos de etnoturismo y productos de artesanías, en vez de reconocer su estatus de personas soberanas" (69). Los indígenas "emprendedores culturales" encarnan con precisión este espíritu de inserción al mercado.

\section{CONCLUSIONES}

Este trabajo estudió la ideología en la cobertura del diario La Nación respecto del conflicto chileno-mapuche durante el primer gobierno de Michelle Bachelet Jeria (2006-2010). Tras una descripción detallada de indígenas y funcionarios gubernamentales, concluimos que "el conflicto chileno-mapuche", como significado flotante sin contenido, intenta ser cooptado por la cobertura de La Nación, un aparato ideológico del Estado, de acuerdo con tres puntos nodales: 
1) El "reconocimiento cultural", donde prima la construcción del indio permitido y la reivindicación cultural. Aquí, el diario destaca los intentos del gobierno por crear una política indígena exitosa, además de resaltar actividades de los mapuche en donde rescatan y renuevan su identidad. Este punto demuestra, a nuestro juicio, que para el oficialismo concertacionista, representado en la cobertura de La Nación, no significa una concesión ideológica o política admitir la importancia del reconocimiento y una deuda histórica con dicho pueblo, como podría ser para un diario de centroderecha o derecha.

2) La "seguridad pública", donde encontramos al indio insurrecto, el control policial y la judicialización del conflicto. Aquí, el gobierno controla y coordina la coerción estatal para contener los aspectos más violentos del conflicto, reconociendo su existencia pero restándoles gravedad. EL indio insurrecto por excelencia es el que pertenece a la Coordinadora Arauco Malleco.

3) La "competencia gubernamental", que refuerza la idea de éxito y gobernabilidad de la Concertación, en la medida en que el gobierno se muestra eficiente en estas dos tareas anteriores, tanto como ejecutor de iniciativas multiculturales como de garante de seguridad y mediador entre los distintos actores del conflicto.

En general, estos tres puntos nodales dan cuenta de un panorama político general. El Estado chileno reconoce una deuda con el pueblo mapuche, y organiza una política indígena de devolución de tierras y de reconocimiento cultural que gira en torno a la idea del indio permitido. Esto está ligado con la idea de construcción de gobernabilidad: levantar una armazón institucional que sintonice con las necesidades de los nuevos desafíos del país, en este caso, del tema indígena.

Luego, para hacer frente a los mapuche que son más críticos y radicales respecto de esta política, que no aceptan o que consideran insuficiente, protestando luego mediante actos de violencia contra la propiedad, el Estado organiza una política de seguridad pública destinada a reprimir las manifestaciones de violencia reivindicativa y proteger el estado de derecho. El indio insurrecto es considerado, entonces, como obstructivo en la creación de gobernabilidad, ya que sus ideas y métodos no son razonables ni se condicen con un espíritu democrático: exigen mucho y lo hacen de forma violenta.

Por último, el diario La Nación, como aparato ideológico del Estado, intenta generar consenso en torno a esta dicotomía, resaltando la importancia institucional del reconocimiento cultural, y las consecuencias negativas -jurídicas y policiales- que sufren los comuneros y comunidades conflictivas. El conflicto, entonces, pareciera emerger solo cuando hay avances institucionales y nuevas políticas indígenas, $\mathrm{o}$ atentados $\mathrm{y}$ acciones de violencia indígena.

\author{
Universidad de Concepción* \\ Facultad de Ciencias Sociales. \\ Departamento de Sociología y Antropología \\ Barrio Universitario s/n 4to. Piso, Oficina 15 Concepción (Chile) \\ c.gonzalez.aburto@gmail.com
}


Los mapuche y personeros de gobierno en la cobertura mediática de La Nación

Universidad de Concepción $* *$
Facultad de Ciencias Sociales.
Departamento de Sociología y Antropología
Barrio Universitario s/n 4to. Piso, Oficina 15 Concepción (Chile)
obarriga@udec.cl

\section{OBRAS CITADAS}

Althusser, Louis. "Ideology and ideological state apparatuses (notes towards an investigation)". Lenin and Philosophy and Other Essays. New York \& London: Monthly Review Press, 1971: 85-126.

_ For Marx. New York: Penguin Press, 1969.

Álvarez San Martín, Roberto. "Imágenes de la prensa, el empresariado y los parlamentarios sobre el conflicto mapuche". Gazeta de Antropología, 27.1 (2011). Web. 15 Marzo, 2014.

Amolef, Andrea, "La alteridad en el discurso mediático: Mapuches y la prensa chilena". Boletín IFP, 2.6 (2004): 7-9.

Bello Maldonado, Álvaro. "Igualdad, diferencia y gobernabilidad en Chile: ¿es posible la justicia social en torno a los valores de una sociedad intercultural?". Justicia social y diversidad. Articulación desde una perspectiva intercultural. Ed. Solange Cárcamo Landero. Temuco: Ediciones UC Temuco, 2009: 37-52.

Boeninger, Edgardo. "La gobernabilidad: un concepto multidimensional". Estudios Internacionales 105 (1994): 79-94.

Camou, Antonio. "Estudio Preliminar". Los desafios de la gobernabilidad. México D.F.: FLACSO, 2001: 15-58.

Del Valle, Carlos. "Interculturalidad e intraculturalidad en el discurso de la prensa: cobertura y tratamiento del discurso de las fuentes en el 'conflicto indígena mapuche', desde el discurso político”. Revista Redes.Com 2 (2005). Web. 10 Marzo 2014.

Hale, Charles R. "Rethinking indigenous politics in the era of "indio permitido"". NACLA Report on the Americas, 38.2 (2004): 16-21.

Insulza, José Miguel. "América Latina: en el umbral del desarrollo y la democracia". Ideas para Chile: aportes de la centroizquierda. Ed. Clarisa Hardy. Santiago: LOM, 2010: 171-187.

Krippendorf, Kraus. Content analysis: an introduction to its methodology. Thousand Oaks: Sage Publications, 2004.

Laclau, Ernesto y Mouffe, Chantal. Hegemonía y estrategia socialista. Madrid: Siglo XXI, 1987.

La Nación. "Ley de seguridad por ataque a bus de pasajeros en Temuco". Diario $L a$ Nación 30 de julio de 2009. Pág. 7. 
Lechner, Norbert. Las sombras del mañana: la dimensión subjetiva de la política. Santiago: LOM, 2002.

Pairicán Padilla, Fernando y Álvarez Vallejo, Rolando. "La Nueva Guerra de Arauco: La Coordinadora Arauco Malleco en el Chile de la Concertación de Partidos por la Democracia (1997- 2009)". Revista www.izquierdas.cl 10 (2011): 66-84. Web, 30 julio 2014.

Richards, Patricia. "Of indians and terrorists: how the state and local elites construct the mapuche in neoliberal multicultural Chile". Journal of Latin American Studies, 42.1 (2010): 59-90.

Troncoso, Patricia y González, Claudio. "Estudio y análisis de la prensa escrita durante los años 1997 al 2002 en torno a la imagen mapuche". A Contracorriente, 11.3 (2014): 139-163. Web, 15 Marzo 2014.

\section{ANEXOS}

A continuación presentamos algunos ejemplos de las unidades de información en las que construimos los diferentes subtipos de actores. Como ya están categorizadas según subtipos, no se incluye el sujeto específico de la oración, sino el subtipo y las acciones que le son asignadas (se trata de nuestra forma de trabajo).

\section{Comuneros Mapuche}

Los activistas

“...ocuparon ayer el consulado chileno en Bariloche...”" (La Nación 3 de mayo de 2006: 6).

“...se tomaron (...) la sede del Arzobispado de Santiago (...) para solicitarle a la Iglesia que interceda en la creación de una mesa de diálogo que estudie las reivindicaciones de los presos mapuches..." (La Nación 30 de noviembre de 2007: 10).

“...hicieron públicas peticiones que ya habían hecho al comisionado para políticas indígenas (...) piden que se estudien, entre otras cosas, Programa Orígenes, violación de derechos humanos e implementación de recomendaciones del relator especial de la ONU..." (La Nación 23 de julio de 2008: 18).

“...las acciones reivindicativas se produjeron por cuarto día consecutivo..." (La Nación 27 de julio de 2009: 11).

“...los habitantes de esa polémica localidad (...) intentaron tomarse un predio del agricultor René Urban...” (La Nación 31 de julio de 2009: 8).

Los procesados

“...fueron detenidos por personal de Carabineros..." (La Nación 16 de noviembre de 2006: 8).

“...fueron trasladados a la Segunda Comisaría de Temuco..." (La Nación 16 de noviembre de 2006: 8).

“...ya están en condiciones de retornar a la cárcel de la capital de la Araucanía...” (La Nación 23 de mayo de 2006: 18).

Los condenados

“...tras ser condenado fue llevado al Tribunal de Garantía de Collipulli, donde se controló su detención y se dispuso su traslado a la Cárcel de Angol, para dar inicio a su cumplimiento de condena..." (La Nación 21 de marzo de 2007: 8). 
“...permanecen recluidos en recintos penales del sur del país, purgando condenas de 10 años de cárcel..." (La Nación 16 de octubre de 2007: 2).

\section{Los culturales}

“...enseña a los niños de su curso a tener respeto por la naturaleza y a entender el significado de la cosmovisión mapuche a través de leyendas y juegos...” (La Nación 5 de octubre de 2007: 23).

"...con sus palines en ristre mantuvieron a distancia prudente a los muchos reporteros gráficos..." (La Nación 16 de octubre de 2007: 2).

\section{Los declaradores}

“...sostuvo que 'debemos avanzar en los temas de derechos indígenas y de la participación en todas las instancias políticas'...” (La Nación 16 de noviembre de 2007: 2).

“...reiteró ayer su rechazo al proyecto de Reconocimiento Constitucional de los Pueblos Indígenas..."(La Nación 2 de septiembre de 2009, Web).

“...(según ellos) la iniciativa 'tiene un carácter genérico y no reconoce el derecho relativo a las tierras, ni a sus recursos, ni el derecho a la participación, ni los principios del derecho a la libre determinación..." (La Nación 2 de septiembre de 2009: 8).

Los ilegales

"...debe cumplir medidas cautelares luego de haber pasado varios meses en prisión..." ( $\mathrm{La}$ Nación 28 de agosto de 2008: 10).

"...todos fueron formalizados por los delitos de robo con violencia, atentado contra la autoridad en el ejercicio de sus funciones y asociación ilícita de carácter terrorista..." (La Nación 14 de abril de 2009: 6).

"... acusados de ser los autores de los disparos de perdigones contra un vehículo particular, la quema de un camión y el robo de 40 mil pesos, dos celulares y una cámara de peaje..." ( $L a$ Nación 20 de octubre de 2009, 8)

\section{Los emprendedores culturales}

"durante nueve años esta mujer mapuche se ha desarrollado en el rubro de la gastronomía intercultural, donde se destaca por la promoción de la identidad culinaria de su pueblo..." ( $\mathrm{La}$ Nación 8 de mayo de 2008. 10).

"...llevan consigo el conocimiento milenario de la curación natural en base a yerbas..." ( $\mathrm{La}$ Nación 26 de febrero de 2008: 17).

Las víctimas de violencia

“...fue alcanzado por una ráfaga de balas que le perforaron el pulmón...” (La Nación 4 de enero de 2008: 2).

“...presentaba una fractura en su brazo izquierdo, producto de un impacto de bala, y diferentes impactos de perdigones en los pies..." (La Nación 25 de junio de 2008: 2).

“...les informaron que en el enfrentamiento del sábado un mapuche perdió un ojo..." (La Nación 3 de agosto de 2009: 6).

“...murió ayer en violentos incidentes con carabineros que desalojaban una toma..." (La Nación 13 de agosto de 2009: 6).

\section{Los familiares}

“...la pérdida de una grabación que exculpa al comunero mapuche Héctor Llaitul Carrillanca fue denunciada por los familiares del líder...” (La Nación 22 de abril de 2008: 9). 


\section{Carlos González Aburto y Omar A. Barriga}

“...afirmaron que él 'fue sometido a torturas con el objeto de que se autoinculpara del atentado incendiario..." (La Nación 3 de junio de 2008: 8).

“...dijo que ni aunque le den cadena perpetua a Walter Ramírez, nadie le devolverá la vida de su hijo...” (La Nación 18 de noviembre de 2009: 10).

Los denunciadores de violencia

“...afirmó que actos de violencia como el que costó la vida a su hijo seguirán ocurriendo 'mientras no haya voluntad política de las autoridades para escuchar al pueblo mapuche'..." ( $\mathrm{La}$ Nación 30 de junio de 2009: 10).

“....añadió que 'estamos absolutamente convencidos de que la desproporción de fuerza fue tremenda'...” (La Nación 30 de junio de 2009: 10).

“...denunciaron ayer un accionar desproporcionado de Carabineros...” (La Nación 30 de julio de 2009: 7).

\section{Líderes Mapuche}

\section{Violentos}

“...agredieron a dos fiscales, a los gendarmes que estaban custodiando el tribunal..." (La Nación 21 de noviembre de 2006: 21).

“...cumple pena remitida por desórdenes públicos y amenazas a personal de carabineros..." ( $\mathrm{La}$ Nación 21 de noviembre de 2006: 21).

\section{Ilegales}

"...fue detenido el viernes en Contulmo, y trasladado bajo fuertes medidas de seguridad hasta Angol..." (La Nación 20 de noviembre de 2006: 7).

“...se encuentra detenido y engrillado a su cama en el hospital..." (La Nación 15 de septiembre de 2008: 10).

“....al ser reconocido fue formalizado por el delito de incendio perpetrado el 2006...” (La Nación 15 de septiembre de 2008. 10).

Procesados y condenados

“...fue detenido en febrero pasado y en su poder tenía un arma de fuego..." (La Nación 30 de agosto de 2007: 8).

“...purgan draconianas penas, ya que se les aplicó Ley Antiterrorista...” (La Nación 29 de noviembre de 2007: 8).

\section{Huelguistas}

“....iniciaron (...) una huelga de hambre para exigir 'libertad inmediata a todos los presos políticos mapuches', 'la desmilitarización de las zonas en conflicto' y el fin a 'la represión a las comunidades'..." (La Nación 16 de octubre de 2007: 2).

“...más de 15 kilos ya han perdido (...) permanecen en huelga de hambre hace 51 días en la cárcel de Angol...” (La Nación 29 de noviembre de 2007: 8).

\section{Declaradores contra el excesivo control}

“...expresar su molesta por 'la política de criminalización y satanización' que ha generado la prensa en contra de la comunidad mapuche..." (La Nación 10 de enero de 2009: 9).

“...afirmó que 'Pérez Yoma ha venido a reafirmar la línea represiva en contra de los mapuches y ha actuado de manera parcial..."' (La Nación 27 de agosto de 2008: 8). 


\section{Denunciantes de violencia}

“...dijo que, al menos, 15 civiles dispararon contra la comunidad, resultando tres mapuches heridos de bala..." (La Nación 3 de agosto de 2007: 6).

"...aseguró que el comuneros habría sido ejecutado por carabineros cuando se encontraba detenido..." (La Nación 13 de agosto de 2009: 6).

“...aseguró que su hijo de 13 años fue golpeado y amarrado en un allanamiento de su comunidad...” (La Nación 23 de octubre 2009: 7).

\section{Políticos}

“... no comulga con la idea de formar un partido político...” (La Nación 15 de mayo de 2006: 16).

“...indica (que) como la idea es gobernar el Wallmapu (...) 'necesitamos un partido para participar en contiendas electorales'...” (La Nación 15 de mayo de 2006: 16).

\section{Declaradores multiculturales}

“...criticó los supuestos acuerdos que están firmando algunas pescadores con Celulosa Arauco..." (La Nación 22 de noviembre de 2007: 21).

“...entrega sus fundamentos. Por primera vez en Chile se instala en el ordenamiento jurídico el concepto de 'pueblos originarios' en vez del añejo concepto 'minorías étnicas'..." (Diario La Nación 22 de noviembre de 2007: 21).

“...añadieron que presentarán una demanda internacional, debido a que no se respetan a sus autoridades (lonkos)..." (La Nación 8 de julio de 2009: 9).

\section{Activos}

“...se opone a una declaración interpretativa que ha impulsado la derecha para aprobar el Convenio 169 de la OIT..." (La Nación 15 de enero de 2008, Web).

“...realizó ayer la Primera Conferencia Nacional sobre el Derecho a la Libre Determinación/Autogobierno en la ciudad de Temuco..." (La Nación 25 de junio de 2008: 3).

\section{Propositivos}

“...explicó que la iniciativa tiene por objeto establecer de manera institucional la participación política de los pueblos indígenas..." (La Nación 10 de septiembre de 2009: 8)

“...pidió ayer al gobierno que aplique la ley de expropiación de tierra, 'teniendo en cuenta que la situación es de interés nacional y público'...” (La Nación 28 de septiembre de 2009: 8).

\section{Críticos del gobierno}

“...han cuestionado las propuestas contenidas en el borrador del gobierno..." (La Nación 14 de junio de 2009: 30).

“...cuestiona la existencia misma del proyecto. A su juicio, desde el punto de vista jurídico, un código se relaciona más con acuerdo entre privados y la autorregulación que con un instrumento de derecho internacional..." (La Nación 14 de junio de 2009: 30).

\section{No recibidos}

“...llegaron ayer hasta La Moneda, pero no pudieron reunirse con la presidenta...” (La Nación 8 de julio de 2009: 9).

"...trataron de llegar hasta la Moneda, para reunirse con la presidenta (...) lo que fue impedido..." (La Nación 28 de julio de 2009: 6). 
3. Miembros de la Coordinadora Arauco Malleco (CAM)

Ilegales

"...fueron formalizados la semana pasada y permanecen en la Cárcel de Alta Seguridad de Santiago..." (La Nación 21 de enero de 2008: 8).

"...había sido capturado (...) acusado de encabezar el atentado incendiario contra la Forestal Mininco..." (La Nación 29 de marzo de 2008: 9).

“...prófugo desde noviembre pasado, fue detenido cerca de Cañete..." (La Nación 26 de marzo de 2008: 8).

“...quedaron en prisión preventiva por el plazo de nueve meses..." (La Nación 13 de abril de 2009: 7).

“...deberá permanecer durante nueve meses en la cárcel El Manzano...” (La Nación 17 de julio de 2009: 8).

Los que alegan inocencia

“... afirmó que se encontraba en otro lugar el día del atentado...” (La Nación 9 de junio de 2008: 10).

“....reiteró que es inocente de los hechos que se le imputan y si bien se reconocía simpatizante de la causa indígena, ello no significaba participación en hechos delictuales..." (La Nación 3 de junio de 2008: 8).

\section{La institución}

"...se mantiene en estado de cautela respecto de lo que vendrá luego de la muerte de Matías Catrileo..." (La Nación 6 de enero de 2008, Web).

"...ya no tiene líderes en libertad (...) por lo que la organización mapuche de declaró en 'reorganización'...” (La Nación 29 de marzo de 2008: 9).

\section{Huelguistas}

“....iniciaron ayer una huelga de hambre indefinida, en protesta por la decisión de Gendarmería de trasladarlos a otros penales para separarlos..." (La Nación 20 de agosto de 2009: 3).

"....se declararon el martes pasado en huelga de hambre indefinida en protesta por el traslado. Estiman que atenta contra una eficaz defensa..." (La Nación 21 de agosto de 2009: 3).

\section{Adjudicadores de atentados}

“...se adjudicó los últimos atentados incendiarios en la Región de la Araucanía y anunció que continuará 'la lucha de resistencia'..." (La Nación 14 de enero de 2009: 8).

“...se adjudicó los últimos atentados incendiarios en la Región de la Araucanía, en comunicados que la organización hizo llegar a medios...” (La Nación 7 de septiembre de 2009: 7).

\section{Personeros de gobierno}

\section{Hacedores}

“...envió ayer con carácter de suma urgencia el proyecto de ley que otorgará el beneficio de la libertad condicional a nueve comuneros mapuches..." (La Nación 16 de mayo de 2006: 18).

“....anunció que para el año 2007 habrá más de 40 mil becas de educación básica, media y superior..." (La Nación 13 de diciembre de 2006: 19). 


\section{Propositivos}

“...nombró (...) como nuevo director del Programa Orígenes a Fernando Quilaleo Aguirre (...) y como fiscal de la Conadi al abogado de la Universidad de Chile Arturo Huenchullán Pino...” ( $L a$ Nación 28 de mayo de 2007: 19).

“...(su propuesta) se basa en cinco ejes: fortalecer las formas de participación de los pueblos originarios en el ámbito político y social, reconocimiento y profundización de derechos política indígena urbana, mujer indígena y educación y cultura..." (La Nación 10 de mayo de 2007: 21). “...comprometió el envío al Congreso de un proyecto de reforma constitucional que reconozca el carácter multicultural de Chile. También se dará urgencia en el Parlamento a la aprobación del Convenio 169 de la OIT..." (La Nación 10 de mayo de 2007: 21).

\section{Activos}

“....señaló que durante los gobiernos de la Concertación, la pobreza en la Araucanía ha disminuido paulatinamente, hasta alcanzar el 13\%...” (La Nación 19 de agosto de 2009: 7).

“...anunció que está en marcha la creación de la subsecretaría indígena...” (La Nación 19 de agosto de 2009: 7).

“...mantuvieron alrededor de 154 reuniones durante el día con delegaciones de Lumaco, Pitrufquén, Vilcún, Ercilla y Freire y representantes de las 155 comunidades que están priorizadas en la entrega de tierras..." (La Nación 20 de agosto de 2009: 2).

\section{Declarantes}

“...explicó anoche que el argumento comparativo para explicar la salida de Parra es muy sencillo: 'es como que el Servicio Nacional de la Mujer (Sernam) no puede ser dirigido por un hombre'..." (La Nación 3 de mayo de 2007: 5).

\section{Multiculturales}

“....comentó que la idea es que para el año 2010 'tengamos vigente en Chile política indígena urbana que haya permitido reconocer en su identidad de derechos'..." (La Nación 13 de diciembre de 2006: 19).

“...reconoció la deuda con los pueblos originarios urbanos..." (La Nación 13 de diciembre de 2006: 19).

“....anunció el envío de un proyecto de ley que crea la Subsecretaría de Asuntos Indígenas...” ( $L a$ Nación 25 de junio de 2008: 2).

“...firmó un instructivo presidencial que ordena la creación de unidades específicas sobre los pueblos originarios en todos los ministerios..." (La Nación 25 de junio de 2008: 2).

“...firmó la ratificación del convenio (169 de la OIT) en agosto de este año...”" (La Nación 15 de octubre de 2008: 20).

\section{Cautelosos}

“...prefirió no evaluar la situación del mapuche baleado hasta conocer el resultado de las investigaciones..." (La Nación 30 de agosto de 2006: 6).

“...explicó que no se pronunciará ya que estimó más apropiado esperar que ambas investigaciones demuestren si todo se hizo acorde a la norma..." (La Nación 30 de agosto 2006: 6). 
Negociadores

“...se había comprometido a designar dentro de las próximas 48 horas un mediador para que inicie gestiones tendientes a que los comuneros puedan deponer la prolongada huelga..." ( $L a$ Nación 29 de noviembre de 2007: 8).

"...ha estado en permanente contacto con las autoridades de Gendarmería, familiares y huelguistas y no descartó que ante una condición crítica de los ayunantes de les traslade a un centro asistencial..." (La Nación 13 de diciembre de 2007: 8).

“....aceptó la propuesta respecto a los beneficios carcelarios que ésta hizo llegar a las autoridades mediante el presidente de la conferencia episcopal...” (La Nación 29 de enero de 2008, Web).

Autorreflexivos

“...señaló que para entonces él no estaba en el gobierno, pero reconoció que ha habido 'cierto elemento de distorsión, hay algunos que están presos por un tipo de ley y otros, por otra'...” ( $L a$ Nación 30 de enero de 2008: 3).

“...señaló que (...) en el ámbitos de los pueblos indígenas se está pasando del hecho de cubrir necesidades a otro punto centrado en derechos..." (La Nación 30 de enero de 2008: 3).

\section{Los que llaman a la calma}

“...desestimó que el ataque con arma de fuego del que fue víctima el gerente de Trayenco (...) haya sido una acción organizada por la CAM (Coordinadora Arauco-Malleco)..." (La Nación 9 de enero de 2008: 9).

“...negó que hubiera una 'guerrilla rural'...” (La Nación 6 de enero d 2008, 12).

“...pidió tranquilidad a la comunidad mapuche del país..." (La Nación 4 de enero de 2008: 3).

Los que bajan el perfil a la violencia

“... agregó que la autoridad no ha sido sobrepasada en este tema..." (La Nación 23 de enero de 2009: 8).

“...afirmó que son sólo dos las comunidades mapuches, dentro de dos mil, que han optado por el camino violentista..." (La Nación 28 de julio de 2009: 6).

“... afirmó además que 'no hay ningún clima de inseguridad'...” (La Nación 30 de julio de 2009:7).

“...dijo que en la Araucanía 'ha habido incidentes, pero aquí no estamos hablando de una región en llamas o algo por el estilo'...” (La Nación 21 de agosto de 2009: 2).

\section{Los que garantizan seguridad}

“... .aclaró la posición de la moneda respecto al conflicto: ‘(...) el gobierno no puede quedar inmóvil si un grupo, grande o pequeño, su forma de hacerse escuchar (sic) es quemando micros, haciendo barricadas o tirando peñascos'..." (La Nación 6 de enero de 2008, Web).

“... dijo que para el Gobierno es muy importante 'la anticipación, prevenir, estar atento a sobre cuáles son los posibles conflictos y buscar todas las medidas para evitar esto'..." (La Nación 30 enero de 2008: 3).

“...detalló algunas de las medidas que se adoptarán, entre ella, aumentar la seguridad para camioneros..." (La Nación 29 de julio de 2009: 7).

“...aclaró ayer que los camioneros de la Araucanía tendrán vigilancia permanente en la ruta que une Collipulli y Freire...”(La Nación 9 de septiembre de 2009: 10). 
Condenadores de violencia

“...repudió la aparición del supuesto comando paramilitar 'Hernán Trizano'...” (La Nación 2 de agosto de 2009: 19).

“...condenó el hecho y pidió mantener la confianza en que las policías aclararán el 'contexto y responsabilidades' en que se produjo la muerte del comuneros..." (La Nación 13 de agosto de 2009: 6). “...lamentó las muerte del comunero de Angol (...y) entregó sus condolencias a los familiares de la víctima Jaime Facundo Mendoza Collío...” (La Nación 14 de agosto de 2009: 6).

Querellantes

“....anunció ayer que el Gobierno se querellará contra los 11 comuneros mapuches detenidos por su presunta participación contra el fiscal especial Mario Elgueta...” (La Nación 13 de abril de 2009: 7). “...presentó una querella por Ley de Seguridad del Estado, por el ataque a un bus de pasajeros..." (La Nación 31 de julio de 2009: 8).

“...condenó los hechos y anunció una querella en contra de quienes resulten responsables..." ( $\mathrm{La}$ Nación 12 de octubre de 2009: 8)

“...condenó los atentados incendiarios contra dos camiones (...) y anunció que el gobierno se querellará por Ley Antiterrorista...” (La Nación 14 de octubre de 2009: 8).

Los que rechazan la especulación de tierras

“...fue tajante al indicar que desde el año pasado hasta la fecha, el valor de las tierras subió 2,7 veces más de lo que realmente hacen (...) añadió que el gobierno tomará medidas ante esta situación..." (La Nación 21 de agosto de 2009: 2).

“....informó que 'vamos a cambiar las normas de adjudicación de tierras, porque las actuales favorecen la especulación'...” (La Nación 28 de septiembre de 2009: 8). 